\title{
Investigation of SARS-CoV-2 Ability to Pass Through the Placenta
}

\author{
Fahimeh Ghotbizadeh ${ }^{1}$, Farzaneh Nazari ${ }^{2,}{ }^{*}$, Sedigheh Hantoushzadeh ${ }^{1}$, Zahra Panahi ${ }^{1}$ and Zahra \\ Naeiji $^{3}$ \\ ${ }^{1}$ Department of Obstetrics and Gynecology, Tehran University of Medical Sciences, Tehran, Iran \\ ${ }^{2}$ Department of Obstetrics and Gynecology, Bushehr University of Medical Sciences, Bushehr, Iran \\ ${ }^{3}$ Department of Obstetrics and Gynecology, Shahid Beheshti University of Medical Sciences, Tehran, Iran \\ "Corresponding author: Department of Obstetrics and Gynecology, Bushehr University of Medical Sciences, Bushehr, Iran. Email: nazarif78@yahoo.com \\ Received 2020 October 05; Revised 2020 November 21; Accepted 2020 December 14.
}

\begin{abstract}
Context: Recently, a new coronavirus (SARS-CoV-2) as the cause of COVID-19 has made a global health crisis and a great challenge. Pregnant women and fetuses are among the high-risk groups for COVID-19. In this review, we summarize studies regarding SARS-CoV2 virus-placenta interactions at the maternal-fetal interface by demonstrating the pathogenicity of the virus and defense methods of the placenta.

Evidence Acquisition: In the present study, a search was done in domestic and international databases including Google Scholar, Web of Science, PubMed, and Scopus using specific keywords ("Coronavirus" OR “COVID-19" OR "SARS-CoV-2") AND ("Fetus" OR "Placenta") AND ("Pregnancy"), limited until August 2020. Finally, we reviewed 250 articles.

Results: Generally, the pathogenicity and the life cycle of SARS-CoV-2 and virus entry and replication methods allow the virus to pass through the placenta, although there are hormonal and immune barriers in the placenta against SARS-CoV-2, such as placental type interferons.
\end{abstract}

Conclusions: The SARS-CoV-2 can pass through the placenta, but there are defense methods against it.

Keywords: SARS-CoV-2, Placenta, Fetus, Pregnancy, COVID-19

\section{Context}

Since December 2019, the COVID-19 outbreak has turned into a significant global public health threat $(1,2)$. According to studies, this disease is transmitted personto-person via respiratory viral droplets $(3,4)$, which led to the COVID-19 pandemic. Pregnant women and fetuses are among the high-risk groups for COVID-19. Due to the rapid spreading of COVID-19, fetal health is a serious concern. Nonetheless, sufficient data are not available regarding COVID-19 evaluation and management in pregnant women, and the possible vertical transmission risk is unclear (5).

The placenta, an entirely specialized organ, is vital for normal fetus growth and development during pregnancy (6). It supplies the fetus with oxygen and nutrients and removes the wastes and carbon dioxide. Besides substance transfer, the placenta acts as a barrier and prevents fetal exposure to potentially dangerous substances in the maternal blood. However, it cannot completely exclude all dangerous substances and prevent fetal exposure. Moreover, the placenta, as well as metabolizing some substances. Nevertheless, the virus passage from the placental barrier depends on the placental membrane's physical properties and the viral particle biological properties. We intended to assess whether SARS-CoV-2 could cross the placenta. For this purpose, SARS-CoV-2 entry, pathogenicity, and replication methods were discussed in addition to the placental defense methods. Substantial research and time are required to understand how this virus may involve the fetus.

\section{The Life Cycle of SARS-CoV-2 and the Pathogen Char- acteristics}

\subsection{Morphology, Structure, and Stability of SARS-CoV-2}

The large pleomorphic spherical coronavirus particles have surface crown-like projections. The coronavirus diameter ranges from $75 \mathrm{~nm}$ to $160 \mathrm{~nm}$ (an average of 120 $\mathrm{nm})(7,8)$. The virion of SARS-CoV-2 is spherical and has a mean diameter of $78 \mathrm{~nm}$. A lipid bilayer covers this virus where the envelope (E), membrane (M), and spike (S) structural proteins are located. As a beta coronavirus subset, SARS-CoV-2 has shorter spike-like surface proteins, which are known as hemagglutinin esterase (HE) (9). A nucleocapsid is inside the envelope, which is formed by several 
copies of nucleocapsid $(\mathrm{N})$ proteins, which are attached to the single-stranded positive-sense RNA genome in an uninterrupted beads-on-a-string type shape. The genome length ranges between 26 and 32 kilobases $(\mathrm{kb})$, which is the largest genome among the RNA viruses. This genome codes two proteases (polyproteins) (10).

Usually, its molecular weight is $5.5-6.1 \times 10^{6}(11)$. The membrane proteins, lipid bilayer envelope, and nucleocapsid protect this virus out of the host cell. Coronaviruses are stable at $4^{\circ} \mathrm{C}$, room temperature $\left(20^{\circ} \mathrm{C}\right.$, ) and $37^{\circ} \mathrm{C}$ for a minimum of $2 \mathrm{~h}$ without a significant change in their infectious ability. However, they are noninfectious when exposed to $56^{\circ} \mathrm{C}, 67^{\circ} \mathrm{C}$, and $75^{\circ} \mathrm{C}$ for 90,60 , and $30 \mathrm{~min}$, respectively. Sixty minutes of UV irradiation destroys the viral infectivity in the culture medium at an undetectable level. Evidence suggests the great survival of the coronavirus in the environment and human specimens. It should be noted that UV irradiation and heating are effective methods for the eradication of viral infectivity $(12,13)$.

\subsection{Pathogenicity and Entry Methods of SARS-CoV-2}

First, the virus should cross the cell membrane, which is rich in cholesterol and sphingolipid. The SARS-CoV-2 envelope should be bound to the membrane of the host cell for delivering the nucleocapsid to the host cell. Thanks to specific domains of protein S, SARS-CoV-2 binds to the surface molecules of the cell. The virus entry is mediated by the spike (S) glycoprotein, which is a key factor and known as the SARS-CoV-2 cell receptor, and plays a significant role in disease transmission and human infection (Figure 1) (14).

Using receptor binding, proteolytic activation, and low $\mathrm{pH}$ exposure, the protein $\mathrm{S}$ shape is changed for cell entry (15). Cathepsin L, a protease associated with endosomal membranes, promotes viral infectivity through transforming the uncleaved S polypeptides to S1 and S2 proteins. Multiple strategies are available for spike protein proteolytic activation, such as cell surface transmembrane protease/serine (TMPRSS) proteases, trypsin, and furin. The host cell serine protease TMPRSS2 primes the SARS-CoV-2 $\mathrm{S}$ protein for cell entry $(16,17)$.

\subsection{Replication}

After cell entry, SARS-CoV-2 should replicate in the cytoplasm in which viral RNA is replicated (18). Replicase, a viral RNA polymerase, is the first gene that is translated, which produces negative-strand full-length copies of the genome to provide mRNAs for the viral genes. In an infected cell with SARS-CoV-2, large granular areas may be detected, which contain viral RNA and proteins. The viral particles are collected in the Golgi body and vesicles, where the virus particles are transferred to the surface of the cell to be released by exocytosis (Figure 1) (19).

\section{Defense Methods of Placenta}

\subsection{Physicochemical and Structural Properties of Placenta Against SARS-CoV-2}

As a mediator between the fetus and mother, the placenta plays several vital roles. It prevents fetal allograft rejection, protects the fetus, exchanges the nutrients and respiratory gases, removes fetal waste products, and releases steroid and peptide hormones, which are crucial for fetus growth and development. The placenta syncytiotrophoblast layer is a major site for respiratory gas and nutrient exchange between the fetus and the maternal bloodstream (Figure 2) $(20,21)$. Several mechanisms are involved in this exchange: endocytosis, exocytosis, transcellular transfer (22), simple diffusion (23), and solvent drag (24). A receptor may mediate exocytosis and endocytosis processes, which is stimulated by a specific solutereceptor interaction on the cellular membrane (25). The transfer is affected by many factors, including the surface area, thickness, and metabolism of the planta, as well as fetal and maternal blood pH, uteroplacental blood flow, viral molecular weight, presence of viral transporters of the placenta, protein binding, lipid solubility, cross-placental concentration gradient, degree of ionization, and molecular weight $(20,26)$.

With a molecular weight of $5.5-6.1 \times 10^{6}$, SARS-CoV-2 may cross the placenta through the endocytosis process. The average chorionic artery $\mathrm{pH}$ is 7.31 (27). As known, SARS$\mathrm{CoV}-2$ requires a low $\mathrm{pH}$ for cell endosomal entry. The receptor of SARS-CoV-2, ACE2, is widespread in the cells of the maternal-fetal interface such as stromal cells, placental cytotrophoblast, and syncytiotrophoblast, as well as perivascular cells of the decidua. The high ACE2 expression in these cells shows that the placenta may be potentially infected with SARS-CoV-2 (28). Proteases, such as TMPRSS2, are required for the conformational change of protein $S$. Besides, TMPRSS2 mRNA expression is reported in the placenta (29).

The polymerase is required for SARS-CoV-2 replication. Three kinds of polymerases are present in the placenta. The activity of them is high in early pregnancy due to placental formation and mitosis, though it is low during the second trimester. The polymerase $\beta$ activity does not change remarkably during pregnancy (30).

\subsection{Hormonal and Immune Protection of the Placenta}

de Goffau et al. (31) failed to find supporting evidence for the presence of the placental microbiome. However, 


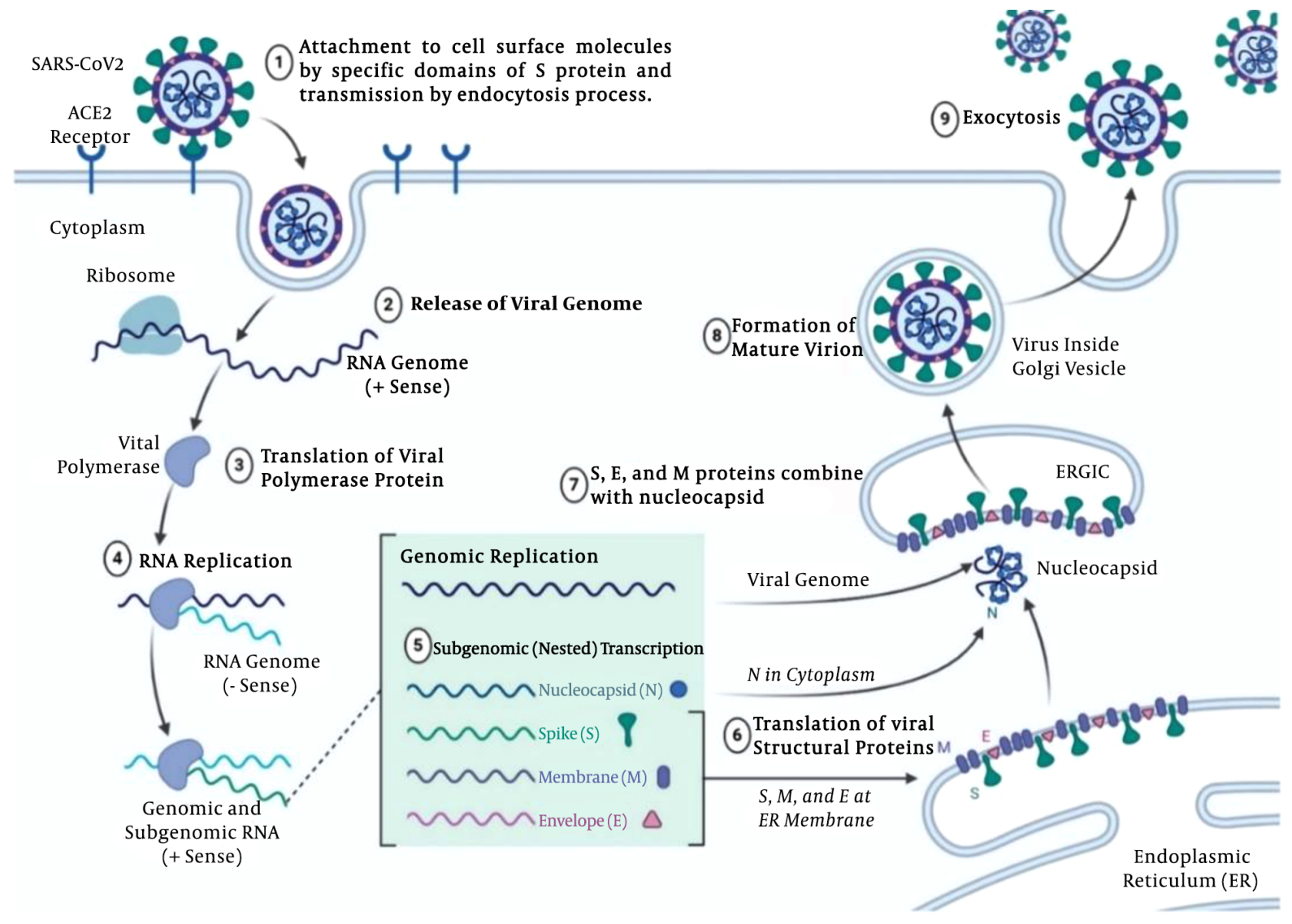

Figure 1. SARS-CoV-2 Life cycle and pathogenicity in nine stages; the virus-cell entry through the endocytosis process via ACE2 receptors; viral replication by polymerase and producing negative-strand full-length copies of the genome to provide mRNAs for the viral genes; viral particle gathering in the Golgi; viral particle release by exocytosis (figure was made using biorender.com).

they recognized a significant pathogen, S. agalactiae, in the placenta of nearly $5 \%$ of women before labor onset (31). The placenta is a tough immune organ by itself. When exposed to pathogens, it expresses pattern recognition receptors (PRR) and, in this way, responds to pathogens at the fetalmaternal interface $(32,33)$.

A study showed that SARS-CoV-2 pathogenesis is mainly caused by the inflammatory response (34). The innate immune system is the first line of defense against this pathogen. The most significant immunomodulators are the placental type interferons (IFNs), which support pregnancy. In the case of a viral infection, interferons I and III function as the antiviral defense responses $(35,36)$. The interferon I antiviral activity directly inhibits the replication of the virus. It also mediates both innate and adaptive cellular immune functions to produce resistance against viral infections and manage long-term immunity. Interferons I and III are strong placental antiviral proteins (Figure 2) (3739).
Some viruses can inhibit the interferon I pathway and thus lead to the replication of the virus and infection. A great deal of the structural, nonstructural, and accessory proteins of coronaviruses have been shown to antagonize the response of IFNs. Besides the proteins, the genome of the coronavirus also encodes non-coding RNAs (ncRNAs). An N gene small ncRNA inhibition has been associated with reduced inflammation (40). These data are in line with the hypothesis stating that SARS-CoV-2 may potentially cross the placenta (Figure 3). Yet, can the crossed virus cause fetal infection? SARS-CoV-2 is a novel and an unknown virus. Many studies are required to further learn about SARS-CoV2 .

\section{Evidence Supporting SARS-CoV-2 Crossing the Pla- centa}

The Zeng et al. (41) study of antibodies in the infants of mothers suffering from COVID-19 pneumonia demon- 


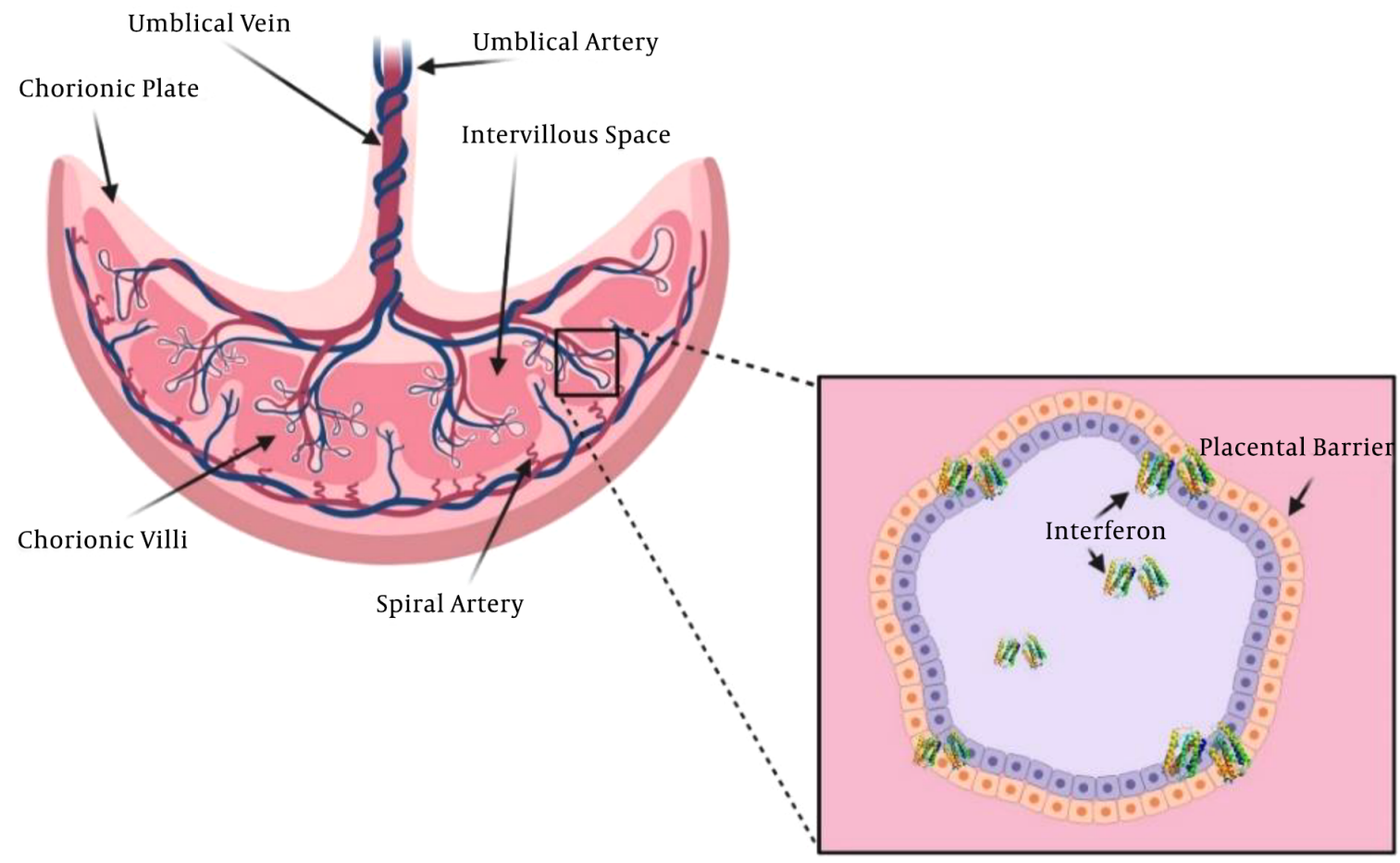

Figure 2. Placental barrier, immunological and physical defenses (figure was made using biorender.com).

strated elevated IgG levels in five infants and IgM detection in two infants at birth. Although IgG antibodies passively transfer across the placenta, IgM antibodies do not usually cross the placenta due to their larger molecular sizes. Hence, IgM might have been synthesized by the infant in the case of the SARS-CoV-2 cross (41). In another study, Algarroba et al. (42) identified coronavirus virions invading syncytiotrophoblasts in placental villi by using electron microscopy in a woman at 28 weeks' gestation due to severe COVID-19 infection. Vivanti et al. (43) demonstrated the transplacental transmission of SARS-CoV-2 in a neonate born to a mother infected in the last trimester presenting with neurological compromise, confirmed by comprehensive virological and pathological investigations.

\section{Evidence Against SARS-CoV-2 Crossing the Placenta}

The only published study on the placental pathology of seven pregnant women with SARS-CoV-2 was conducted by $\mathrm{Ng}$ et al. (44), which reported abnormal placenta in the acute phase of COVID-19, as well as COVID-19 cases in the third trimester. The pathology reports indicated elevated intervillous and subchorionic fibrin and diffuse fetal thrombotic vasculopathy in the avascular chorionic villi areas. Interestingly, villitis, as an important manifestation of placental inflammation, was not recognized. Villitis is a major histologic sign in various maternal infections, which are hematogenously transmitted to the fetus via the placenta (44).

Schwartz (45) investigated 38 pregnant women who suffered from COVID-19. They reported that SARS-CoV-2 was not transmitted through the intrauterine or transplacental routes from infected pregnant women to the fetuses (45). They reported two neonatal COVID-19 cases, both of which failed to provide sufficient evidence to prove vertical transmission due to delayed testing or the potential transmission through a postpartum-infected contact (46, 47). Also, Chen et al. (48) did not report any evidence of positive COVID-19 diagnostic tests or symptoms in the infants of symptomatic, test-positive mothers. In another paper (letter to the editor), Kniss (49) proposed that the structures identified by Algarroba et al. are clathrin-coated vesicles, not SARS-CoV-2 particles (42).

\section{Conclusions}

A very serious complication of viral infections during pregnancy is vertical transmission. Except for the herpes virus, the maternal-fetal transmission of viral diseases 


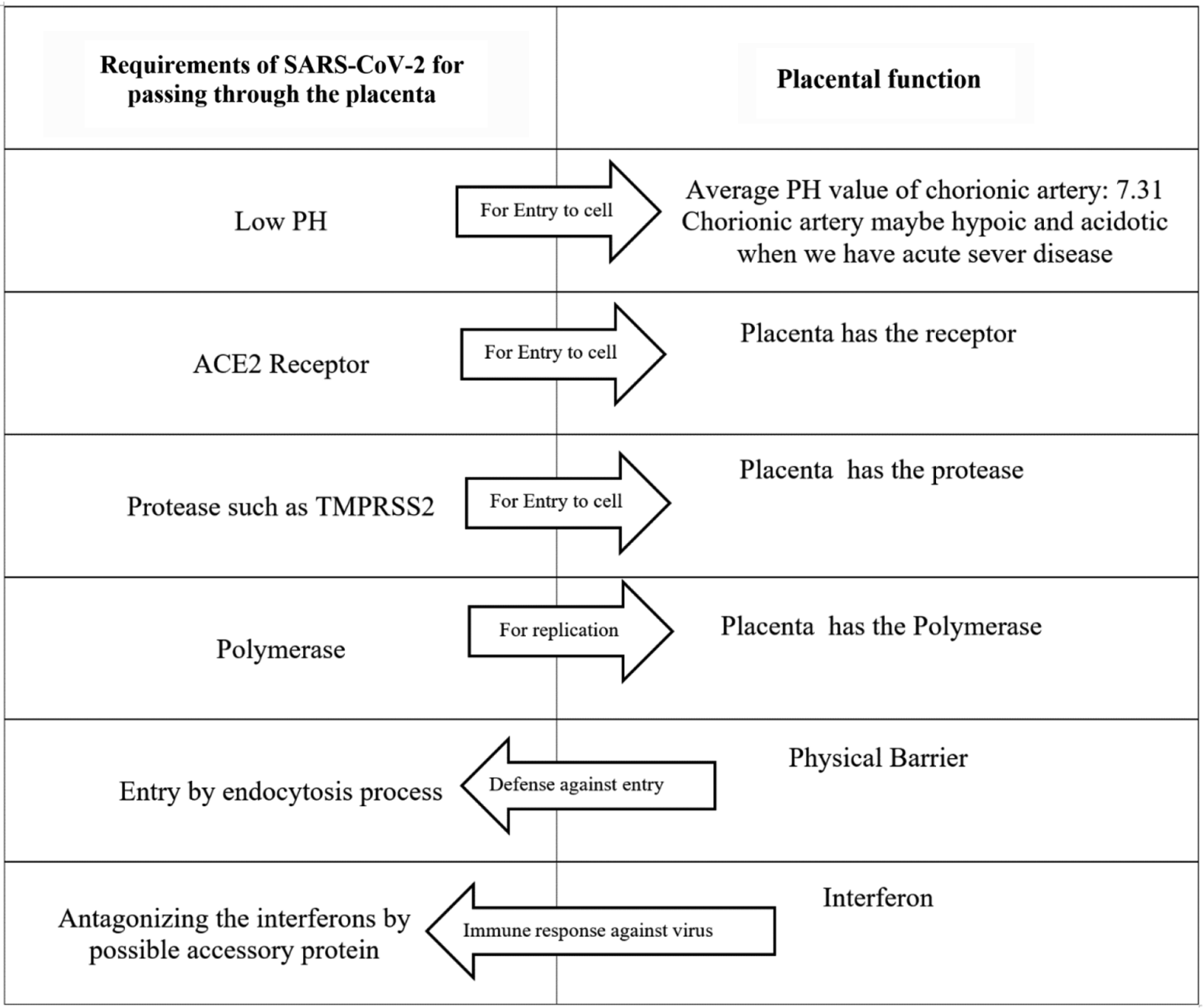

Figure 3. SARS-CoV-2 requirements for crossing the placenta and function of the placenta

commonly occurs via the hematogenous route. Teratogenicity and fetal growth and development impairment are among the known adverse effects of viral transplacental passage. This highlights the significance of investigating potential placental involvement in pregnant women who are infected with SARS- CoV-2.

Although the data is in line with the hypothesis of the SARS-COV-2 passage through the placenta, the placental defense system protects clinically against significant placental infection. It should be noted that intrauterine fetal growth restriction and maternal comorbidities, including gestational diabetes and preeclampsia, may damage the placental barrier by several mechanisms such as abnormal cytotrophoblast differentiation, defective placental angiogenesis, and placental ischemia. These mechanisms in- crease the risk of SARS-CoV-2 intrauterine transmission to the fetus. The growing knowledge of the placental defense mechanisms, as well as the immunological and hormonal responses, may help develop new antiviral agents.

\section{Footnotes}

Authors' Contribution: FGH conceived, designed the evaluation, and drafted the manuscript. FN participated in designing the study, helped draft the manuscript, and collect the data. SH re-evaluated the data and revised the manuscript. ZP collected the data, interpreted them, and revised the manuscript. $\mathrm{ZN}$ re-analyzed the data and revised the manuscript. All authors read and approved the final manuscript. 
Conflict of Interests: None.

Funding/Support: None.

\section{References}

1. Li Q, Guan X, Wu P, Wang X, Zhou L, Tong Y, et al. Early Transmission Dynamics in Wuhan, China, of Novel Coronavirus-Infected Pneumonia. N Engl J Med. 2020;382(13):1199-207. doi: 10.1056/NEJMoa2001316. [PubMed: 31995857]. [PubMed Central: PMC7121484].

2. Guo YR, Cao QD, Hong ZS, Tan YY, Chen SD, Jin HJ, et al. The origin, transmission and clinical therapies on coronavirus disease 2019 (COVID-19) outbreak-an update on the status. Mil Med Res. 2020;7(1):11. doi: 10.1186/s40779-020-00240-0. [PubMed: 32169119]. [PubMed Central: PMC7068984].

3. Hemida MG, Ba Abduallah MM. The SARS-CoV-2 outbreak from a one health perspective. One Health. 2020;10:100127. doi: 10.1016/j.onehlt.2020.100127. [PubMed: 32292814]. [PubMed Central: PMC7102578].

4. Adhikari SP, Meng S, Wu YJ, Mao YP, Ye RX, Wang QZ, et al. Epidemiology, causes, clinical manifestation and diagnosis, prevention and control of coronavirus disease (COVID-19) during the early outbreak period: a scoping review. Infect Dis Poverty. 2020;9(1):29. doi: 10.1186/s40249-020-00646-x. [PubMed: 32183901]. [PubMed Central: PMC7079521]

5. Luo Y, Yin K. Management of pregnant women infected with COVID19. Lancet Infect Dis. 2020;20(5):513-4. doi:10.1016/S1473-3099(20)301912. [PubMed: 32220285]. [PubMed Central: PMC7156224].

6. Gude NM, Roberts CT, Kalionis B, King RG. Growth and function of the normal human placenta. Thromb Res. 2004;114(5-6):397-407. doi: 10.1016/j.thromres.2004.06.038. [PubMed: 15507270].

7. Guy JS, Breslin JJ, Breuhaus B, Vivrette S, Smith LG. Characterization of a coronavirus isolated from a diarrheic foal. J Clin Microbiol. 2000;38(12):4523-6. doi: 10.1128/JCM.38.12.4523-4526.2000. [PubMed: 11101590]. [PubMed Central: PMC87631].

8. Neuman BW, Adair BD, Yoshioka C, Quispe JD, Orca G, Kuhn P, et al. Supramolecular architecture of severe acute respiratory syndrome coronavirus revealed by electron cryomicroscopy. J Virol. 2006;80(16):7918-28. doi: 10.1128/JVI.00645-06. [PubMed: 16873249]. [PubMed Central: PMC1563832]

9. Schoeman D, Fielding BC. Coronavirus envelope protein: current knowledge. Virol J. 2019;16(1):69. doi: 10.1186/s12985-019-1182-0. [PubMed: 31133031]. [PubMed Central: PMC6537279].

10. Modrow S, Falke D, Truyen U, Schätzl H. Molecular Virology. Berlin, Heidelberg: Springer; 2013. doi: 10.1007/978-3-642-20718-1.

11. [No authors listed]. Ter Meulen V, editor. Biochemistry and Biology of Coronaviruses, Sprinter Science and Business Media. 2013.

12. Duan SM, Zhao XS, Wen RF, Huang JJ, Pi GH, Zhang SX, et al. Stability of SARS coronavirus in human specimens and environment and its sensitivity to heating and UV irradiation. Biomed Environ Sci. 2003;16(3):246-55. [PubMed: 14631830].

13. Weiss SR, Navas-Martin S. Coronavirus pathogenesis and the emerging pathogen severe acute respiratory syndrome coronavirus. $\mathrm{Mi}$ crobiol Mol Biol Rev. 2005;69(4):635-64. doi: 10.1128/MMBR.69.4.635664.2005. [PubMed: 16339739]. [PubMed Central: PMC1306801].

14. Wang H, Yang P, Liu K, Guo F, Zhang Y, Zhang G, et al. SARS coronavirus entry into host cells through a novel clathrin- and caveolae-independent endocytic pathway. Cell Res. 2008;18(2):290301. doi: 10.1038/cr.2008.15. [PubMed: 18227861]. [PubMed Central: PMC7091891]

15. Belouzard S, Millet JK, Licitra BN, Whittaker GR. Mechanisms of coronavirus cell entry mediated by the viral spike protein. Viruses. 2012;4(6):1011-33. doi: 10.3390/v4061011. [PubMed: 22816037]. [PubMed Central: PMC3397359].
16. Hoffmann M, Kleine-Weber H, Schroeder S, Kruger N, Herrler T, Erichsen S, et al. SARS-CoV-2 Cell Entry Depends on ACE2 and TMPRSS2 and Is Blocked by a Clinically Proven Protease Inhibitor. Cell.2020;181(2):271280 e8. doi: 10.1016/j.cell.2020.02.052. [PubMed: 32142651]. [PubMed Central: PMC7102627].

17. Millet JK, Whittaker GR. Host cell proteases: Critical determinants of coronavirus tropism and pathogenesis. Virus Res. 2015;202:120-34 doi: 10.1016/j.virusres.2014.11.021. [PubMed: 25445340]. [PubMed Central: PMC4465284]

18. Jackson WT, Giddings TJ, Taylor MP, Mulinyawe S, Rabinovitch M, Kopito RR, et al. Subversion of cellular autophagosomal machinery by RNA viruses. PLoS Biol. 2005;3(5). e156. doi 10.1371/journal.pbio.0030156. [PubMed: 15884975]. [PubMed Central: PMC1084330].

19. Goldsmith CS, Tatti KM, Ksiazek TG, Rollin PE, Comer JA, Lee WW, et al. Ultrastructural characterization of SARS coronavirus. Emerg Infect Dis. 2004;10(2):320-6. doi: 10.3201/eid1002.030913. [PubMed: 15030705]. [PubMed Central: PMC3322934].

20. Griffiths SK, Campbell JP. Placental structure, function and drug transfer. Continuing Educ Anaesth Critical Care Pain L. 2015;15(2):84-9. doi: 10.1093/bjaceaccp/mku013.

21. Mushambi MC, Pinnock C, Lin T, Smith T. Physiology of pregnancy, Fundamentals of Anaesthesia. 2002. p. 511-27.

22. Liu H, Wintour EM. Aquaporins in development - a review. Reprod Biol Endocrinol. 2005;3:18. doi: 10.1186/1477-7827-3-18. [PubMed: 15888206] [PubMed Central: PMC1156947].

23. Sibley CP, Boyd RD. Mechanisms of Transfer Across the Human Placenta. In: Fox PA, editor. Fetal and Neonatal Physiology. Philadelphia: WB Saunders Co; 2004. p. 111-22. doi: 10.1016/b978-0-7216-96546.50016-3.

24. Brownbill P, Mahendran D, Owen D, Swanson P, Thornburg KL, Nelson DM, et al. Denudations as paracellular routes for alphafetoprotein and creatinine across the human syncytiotrophoblast. Am J Physiol Regul Integr Comp Physiol. 2000;278(3):R677-83. doi: 10.1152/ajpregu.2000.278.3.R677. [PubMed: 10712288].

25. Alberts B, Johnson A, Lewis J. Molecular Biology of the Cell. Transport into the Cell from the Plasma Membrane: Endocytosis. 4th ed. New York: Garland Science; 2002.

26. Leon-Juarez M, Martinez-Castillo M, Gonzalez-Garcia LD, HelgueraRepetto AC, Zaga-Clavellina V, Garcia-Cordero J, et al. Cellular and molecular mechanisms of viral infection in the human placenta. Pathog Dis. 2017;75(7). doi: 10.1093/femspd/ftx093. [PubMed: 28903546]. [PubMed Central: PMC7108519].

27. Fujikura T, Yoshida J. Blood gas analysis of placental and uterine blood during cesarean delivery. Obstet Gynecol. 1996;87(1):133-6. doi: 10.1016/0029-7844(95)00300-2. [PubMed: 8532249].

28. Li L, Li R, Wu X. The reciprocal relation between morphological awareness and spelling in Chinese: A longitudinal study of primary school students. PLoS One. 2020;15(12). e0243050. doi 10.1371/journal.pone.0243050. [PubMed: 33347514]. [PubMed Central: PMC7751876].

29. Zmora P, Moldenhauer AS, Hofmann-Winkler H, Pohlmann S. TMPRSS2 Isoform 1 Activates Respiratory Viruses and Is Expressed in Viral Target Cells. PLoS One. 2015;10(9). e0138380. doi: 10.1371/journal.pone.0138380. [PubMed: 26379044]. [PubMed Central: PMC4574978].

30. Seal G, Shearman CW, Loeb LA. On the fidelity of DNA replication. Studies with human placenta DNA polymerases. J Biol Chem. 1979;254(12):5229-37. [PubMed: 447644].

31. de Goffau MC, Lager S, Sovio U, Gaccioli F, Cook E, Peacock SJ, et al. Human placenta has no microbiome but can contain potential pathogens. Nature. 2019;572(7769):329-34. doi: 10.1038/s41586-0191451-5. [PubMed: 31367035]. [PubMed Central: PMC6697540].

32. Abrahams VM. Pattern recognition at the maternal-fetal interface Immunol Invest. 2008;37(5):427-47. doi: 10.1080/08820130802191599. [PubMed: 18716932]. 
33. Lee JK, Oh SJ, Park H, Shin OS. Recent Updates on Research Models and Tools to Study Virus-Host Interactions at the Placenta. Viruses. 2019;12(1). doi: 10.3390/v12010005. [PubMed: 31861492]. [PubMed Central: PMC7020004].

34. Gorbalenya AS, Baric RS; Coronaviridae Study Group of the International Committee on Taxonomy of; et al. The species Severe acute respiratory syndrome-related coronavirus: classifying 2019nCoV and naming it SARS-CoV-2. Nat Microbiol. 2020;5(4):536-44 doi:10.1038/s41564-020-0695-z. [PubMed: 32123347]. [PubMed Central: PMC7095448].

35. Garcia-Sastre A, Biron CA. Type 1 interferons and the virus-host relationship: a lesson in detente. Science. 2006;312(5775):879-82. doi 10.1126/science.1125676. [PubMed:16690858].

36. Sallard E, Lescure FX, Yazdanpanah Y, Mentre F, Peiffer-Smadja N. Type 1 interferons as a potential treatment against COVID-19. Antiviral Res. 2020;178:104791. doi: 10.1016/j.antiviral.2020.104791. [PubMed: 32275914]. [PubMed Central: PMC7138382].

37. Zhou JH, Wang YN, Chang QY, Ma P, Hu Y, Cao X. Type III Interferons in Viral Infection and Antiviral Immunity. Cell Physiol Biochem. 2018;51(1):173-85. doi: 10.1159/000495172. [PubMed: 30439714].

38. Nelemans T, Kikkert M. Viral Innate Immune Evasion and the Pathogenesis of Emerging RNA Virus Infections. Viruses. 2019;11(10) doi: 10.3390/v11100961. [PubMed: 31635238]. [PubMed Central: PMC6832425]

39. Yan Y, Shin WI, Pang YX, Meng Y, Lai J, You C, et al. The First 75 Days of Novel Coronavirus (SARS-CoV-2) Outbreak: Recent Advances, Prevention, and Treatment. Int J Environ Res Public Health. 2020;17(7) doi: 10.3390/ijerph17072323. [PubMed: 32235575]. [PubMed Central: PMC7177691]

40. Periwal N, Sarma S, Arora P, Sood V. In-silico analysis of SARS-CoV2 genomes: Insights from SARS encoded non-coding RNAs. BioRxiv. 2020. doi: 10.1101/2020.03.31.018499.

41. Zeng $\mathrm{H}, \mathrm{Xu} \mathrm{C}$, Fan J, Tang Y, Deng Q, Zhang W, et al. Antibodies in Infants Born to Mothers With COVID-19 Pneumonia JAMA. 2020;323(18):1848-9. doi: 10.1001/jama.2020.4861. [PubMed:
32215589]. [PubMed Central: PMC7099444].

42. Algarroba GN, Rekawek P, Vahanian SA, Khullar P, Palaia T, Peltier MR, et al. Visualization of severe acute respiratory syndrome coronavirus 2 invading the human placenta using electron microscopy. Am JObstet Gynecol. 2020;223(2):275-8. doi: 10.1016/j.ajog.2020.05.023. [PubMed: 32405074]. [PubMed Central: PMC7219376].

43. Vivanti AJ, Vauloup-Fellous C, Prevot S, Zupan V, Suffee C, Do Cao J, et al. Transplacental transmission of SARS-CoV-2 infection. Nat Commun. 2020;11(1):3572. doi: 10.1038/s41467-020-17436-6. [PubMed: 32665677]. [PubMed Central: PMC7360599].

44. Ng WF, Wong SF, Lam A, Mak YF, Yao $\mathrm{H}$, Lee $\mathrm{KC}$, et al. The placentas of patients with severe acute respiratory syndrome: a pathophysiological evaluation. Pathology. 2006;38(3):210-8. doi: 10.1080/00313020600696280. [PubMed: 16753741]. [PubMed Central: PMC7131423].

45. Schwartz DA. An Analysis of 38 Pregnant Women with COVID-19, Their Newborn Infants, and Maternal-Fetal Transmission of SARS-CoV-2: Maternal Coronavirus Infections and Pregnancy Outcomes. Arch Pathol Lab Med. 2020. doi: 10.5858/arpa.2020-0901-SA. [PubMed: 32180426].

46. Qiao J. What are the risks of COVID-19 infection in pregnant women? Lancet. 2020;395(10226):760-2. doi: 10.1016/S0140-6736(20)30365-2. [PubMed: 32151334]. [PubMed Central: PMC7158939].

47. Schwartz. COVID-19, SARS-CoV-2 and pregnancy: Does the past predict the present? Contagion Live. 2020, [cited 1 March 2020]. Available from: https://www.contagionlive.com/news/covid19-sarscov2and-pregnancy-does-the-past-predict-the-present.

48. Chen Y, Peng H, Wang L, Zhao Y, Zeng L, Gao H, et al. Infants Born to Mothers With a New Coronavirus (COVID-19). Front Pediatr. 2020;8:104. doi: 10.3389/fped.2020.00104. [PubMed: 32266184]. [PubMed Central: PMC7098456].

49. Kniss DA. Alternative interpretation to the findings reported in visualization of severe acute respiratory syndrome coronavirus 2 invading the human placenta using electron microscopy. Am J Obstet Gynecol. 2020;223(5):785-6. doi: 10.1016/j.ajog.2020.06.016. [PubMed: 32533928]. [PubMed Central: PMC7284243]. 